\title{
Effects of Combined Membrane-Covered Systems on Aerobic Composting of Strawberry Vine and Chicken Manure
}

\author{
Ruirong Li, ${ }^{\text {a,b }}$ Jie Cao, ${ }^{\mathrm{b}}$ Liang Cai, ${ }^{\mathrm{a}, *}$ Pengjun Wang, ${ }^{\mathrm{b}}$ Haoli Qu, ${ }^{\mathrm{b}}$ Mingjiang Chen, \\ Jingjing $\mathrm{Fu}^{\mathrm{b}}{ }^{\mathrm{j}}$ and Yongsheng Chen ${ }^{\mathrm{b}, *}$
}

\begin{abstract}
A combination of semipermeable membrane-covered composting systems and greenhouses was used to investigate the effects of different insulation systems on the aerobic fermentation of mixed raw materials and changes in the characteristics of fermentation feedstock. The combination of semipermeable membrane-covered and greenhouse systems increased the peak temperature by $6.53{ }^{\circ} \mathrm{C}$, the average fermentation temperature by $28.2 \%$, and extended the duration of the effective hightemperature stage of fermentation (temperature $\geq 50^{\circ} \mathrm{C}$ ) by 14 days. The decomposition percentage of solid organic matter in the enhanced group was $11.8 \%$ higher than that in the normal group, and the fermentation cycle was shortened by 5 days. The duplication provided by using both the semipermeable membrane-covered and greenhouse systems was conducive to the harmless treatment of raw materials, promoted the maturity and efficiency of composting, and reduced the content of biologically toxic substances. This study provides a theoretical basis for improving the efficiency of aerobic fermentation and the safe treatment of solid waste.
\end{abstract}

DOI: 10.15376/biores.17.1.1173-1186

Keywords: Aerobic composting; Membrane-covered; Greenhouse; Manure

Contact information: a: School of Energy and Environment, Southeast University (SEU), Nanjing 210096, China; b: Ministry of Agriculture and Rural Affairs, Nanjing Institute of Agricultural Mechanization, Nanjing 210014, China; *Corresponding author: cailiang@seu.edu.cn; cys003@ sina.com

\section{INTRODUCTION}

Aerobic composting technology is one of the most common methods used to dispose of organic solid wastes (Robledo et al. 2020). During trough composting or windrow composting, large amounts of greenhouse gases and unpleasant odors are produced and discharged in an open system (Chen et al. 2018). Composting in a closed system improves the efficiency of the hydrolysis stage and shortens the fermentation cycle (Schlegelmilch et al. 2005). And microbial activity is higher than that of the other composting systems (Komilis et al. 2004; Turan et al. 2009).

Closed composting systems mainly can be divided into reactor composting systems, semipermeable membrane-covered composting systems, and greenhouse composting systems. A reactor composting system is environment-friendly and high-efficiency, but it has a high cost and a limited processing capacity (Ajmal et al. 2020). The greenhouse composting system can beneficially increase the temperature of the composting by the solar energy (Chen et al. 2020). Lin et al. (2020) used a solar composter to generate more heat and promote the temperature of food residue and cellulosic green waste. Solar energy may 
also be used to control the temperature of the composting, relying on solar-heated water (Chen et al. 2014). As the greenhouse helps to preserve the heat inside, a combination of solar-heated air with the greenhouse can bring advantages to the composting (Poblete et al. 2021).

As a new static composting system, a semipermeable membrane-covered composting system is generally covered with a membrane having uniformly distributed pores that prevent the outward diffusion of dust, aerosols, and microorganisms but allow the outward diffusion of micromolecules (Ma et al. 2021). The membrane also protects the composting feedstock from the effects of rain, wind, and other weather factors. In a covered system, an ideal micro-ecological environment is formed and fermentation efficiency is improved (Huang et al. 2018). Previous studies on physicochemical properties, microbial community structure, and gas emission of composting systems showed that semipermeable membrane-covered composting technology was superior to traditional static composting technology (Dhamodharan et al. 2019; Li et al. 2020). Gonzalez et al. (2016) demonstrated that a semipermeable membrane-covered aerobic fermentation system could maintain a higher temperature for a longer time, and the composting cycle can be shortened to 30 days. Covering the system with the membrane improved the seed germination index (GI) and was conducive to the degradation of volatile solids (VS) (Ma et al. 2021). Through semipermeable membrane-covered fermentation technology, Garcia-González et al. (2015) showed that the membrane improved the product quality by absorbing more nitrogen from pig's manure. Semipermeable membrane-covered fermentation technology can effectively kill pathogens and substantially improve the diversity of microorganisms in these systems (Robledo-Mahón et al. 2018, 2019). Ma et al. (2018) showed that the total abundance of bacteria decreased and the diversity increased. During the membrane-covered aerobic composting, an effective strategy to change the structure of bacterial community is to adjust the interval length of aeration (Ma et al. 2020). The covering of the semipermeable membrane reduces the production and emission of $\mathrm{CH}_{4}$ and $\mathrm{NH}_{3}$ by $22.4 \%$ and $18.9 \%$, respectively (Ma et al. 2018). However, the membranes with different pore diameters have different emission reducing effects on $\mathrm{NH}_{3}, \mathrm{CH}_{4}, \mathrm{CO}_{2}$, and $\mathrm{N}_{2} \mathrm{O}$ (Ma et al. 2021). Due to lack of the insulation, the surface layer of the raw materials is greatly affected by the outside temperature in the semipermeable membrane-covered composting system. Pathogenic bacteria in the surface layer may not be completely killed and effective decomposition may not be achieved (Yang et al. 2020). If the semipermeable membranecovered composting system is used in it, the greenhouse can provide solar energy to increase the temperature of the surface layer of raw materials. In this way, the advantages of the two systems are combined to achieve a better fermentation effect.

Recent studies on semipermeable membrane-covered composting systems have focused on the effects of process adjustments such as ventilation methods, heap properties, and membrane performance, on fertilizer quality and gas emissions. The application object is relatively single, mainly consisting of municipal sludge, some livestock, and poultry manure. The research of greenhouse composting system focuses on the different solar heating method such as single solar greenhouse, solar-heated water, and solar-heated air. As far as we know, no prior research has focused on the joint effect given by the semipermeable membrane system combined with solar greenhouse. Therefore, the influence of the combined effect on dynamic parameters of the process and decomposition effect of waste fermentation remains to be studied.

In the present study, the effects were determined for the enhanced membranecovered systems on composting temperature, maturity, and sterilization. Owing to the 
requirements of green agricultural production and rural environmental governance in China, more than 600 million tons of various vegetable straw and fruit wastes and 3.8 billion tons of manure are generated every year, which are required to be reasonably utilized as resources. As of 2019, China has a sown area of strawberries of 126.13 thousand hectares, with an output of 3.2219 million tons, which makes them the world's largest producer and consumer of strawberries. Therefore, we selected wastes generated from the strawberry vine and chicken manure as the main feedstock. In the present study, the different combinations of semipermeable membrane systems and greenhouses were used as composting facilities to comparatively analyze the dynamic changes in the characteristics of fermentation feedstock. This study provides an experimental knowledge basis for the promotion and application of enhanced combinations of membranes in the aerobic composting of straw wastes.

\section{EXPERIMENTAL}

\section{Materials}

\section{Feedstock and inoculum characterization}

Strawberry vine samples were collected from a village in Jurong City, Jiangsu Province, China. The samples were stored after collection and crushed to 3-5 cm sized pieces using a vegetable straw crusher. Fresh chicken manure was taken from a nearby chicken farm and was used as a feedstock. The physical and chemical properties of the raw materials are shown in Table 1, along with the VS content (based on the total wet weight of the sample and total solids [TS] of the sample). A microbial fortification agent developed by the Jiangsu Academy of Agricultural Sciences (Jiangsu Province, Nanjing, China), which contained Bacillus licheniformis, Bacillus subtilis, Streptomyces loucheii, and Aspergillus oryzae, was employed, and the effective number of viable bacteria was greater than or equal to $50 \mathrm{million} / \mathrm{g}$. The microbial fortification agent was inoculated at a concentration of $0.3 \%$. The microbial fortification agent was liquid and was evenly sprayed on the material using a spray system.

Table 1. Characterization of the Raw Materials Used in the Experiments

\begin{tabular}{|c|c|c|c|c|c|}
\hline Parameters & $\begin{array}{c}\text { Moisture } \\
\text { content (\%) }\end{array}$ & $\begin{array}{c}\text { Carbon-nitrogen } \\
\text { ratio }(\%)^{\mathrm{b}}\end{array}$ & $\begin{array}{c}\text { Total solid } \\
\text { content }(\%)^{\mathrm{a}}\end{array}$ & $\begin{array}{c}\text { Volatile solid } \\
\text { content(\%) }\end{array}$ & $\mathrm{pH}$ \\
\hline $\begin{array}{c}\text { Fresh } \\
\text { Strawberry Vine }\end{array}$ & $86.3 \pm 0.16$ & $15.69 \pm 0.07$ & - & - & - \\
\hline $\begin{array}{c}\text { Chicken } \\
\text { Manure }\end{array}$ & $48.76 \pm 0.13$ & $14.24 \pm 0.18$ & $22.9 \pm 0.1$ & $18.1 \pm 0.1$ & $7.6 \pm 0.2$ \\
\hline
\end{tabular}

Note: The letters $a$ and $b$ represent the values based on the total wet weight of the sample and TS of the sample, respectively.

\section{Experimental Design}

As shown in Fig. 1a, four treatments were performed in the experiment: open-air ventilated composting (OV), open-air and membrane-covered ventilated composting (OMV), greenhouse ventilated composting $(\mathrm{GV})$, and greenhouse and membrane-covered ventilated composting (GMV). In the OV and OMV groups, the two experimental groups were placed in an open-air environment. In the GV and GMV groups, the two experimental groups were placed in a greenhouse. The OMV and GMV groups were covered with a 
semipermeable fermentation membrane, and the OV and GV groups were not covered. The experimental designs of the four treatments are presented in Table 2.

Table 2. Experimental Design for Four Treatments of Aerobic Composting

\begin{tabular}{|c|c|c|c|c|}
\hline Treatments & Open-air & Greenhouse & $\begin{array}{c}\text { Semipermeable } \\
\text { Membrane-covered }\end{array}$ & Ventilation \\
\hline OV & $\sqrt{ }$ & $\mathrm{X}$ & $\mathrm{X}$ & $\sqrt{ }$ \\
\hline OMV & $\sqrt{ }$ & $\mathrm{X}$ & $\sqrt{ }$ & $\sqrt{ }$ \\
\hline GV & $\mathrm{X}$ & $\sqrt{ }$ & $\sqrt{ }$ & $\sqrt{ }$ \\
\hline GMV & $\mathrm{X}$ & $\sqrt{ }$ & \\
\hline
\end{tabular}

First, crushed strawberry vines were placed horizontally at the bottom in one layer. The chicken manure and microbial fortification agents were spread evenly on the strawberry vines. This process was repeated until the height of the stacking material was approximately $2.0 \mathrm{~m}$. The carbon-nitrogen ratio $(\mathrm{C} / \mathrm{N})$ and moisture content were adjusted to $30: 1$ and $65 \%$, respectively. Then, the materials were stirred evenly, and a pile was built on top of the pre-laid ventilation system by a forklift. The test stack was a cone with a diameter of $2.0 \mathrm{~m}$ and a height of $1.8 \mathrm{~m}$. The effective volume was approximately $1.5 \mathrm{~m}^{3}$, and the weight of the material was 1 ton. The experimental period spanned 50 days.

$$
\text { a }
$$

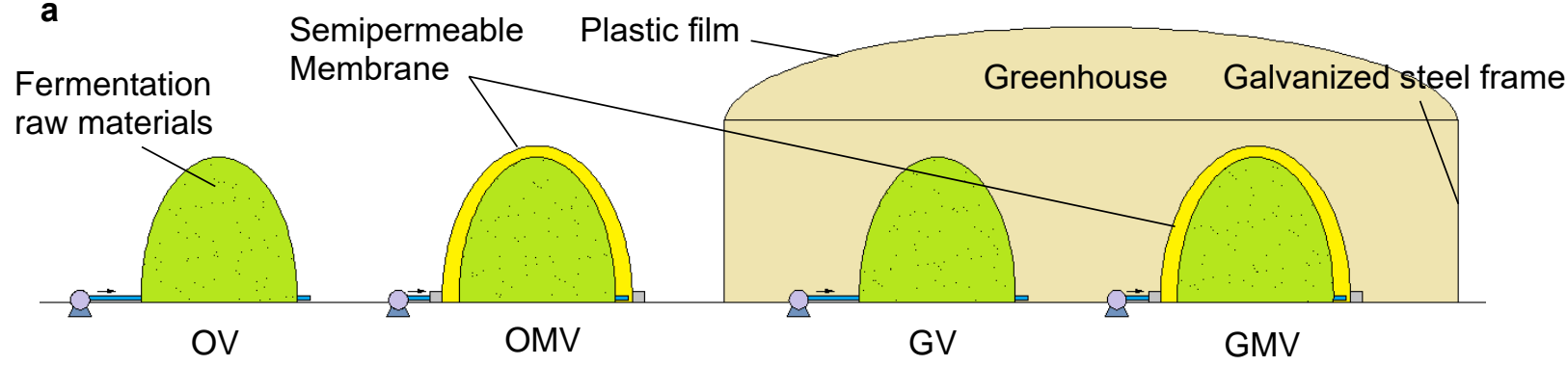

Ventilation ducts $\quad$ Fermentation raw materials

b

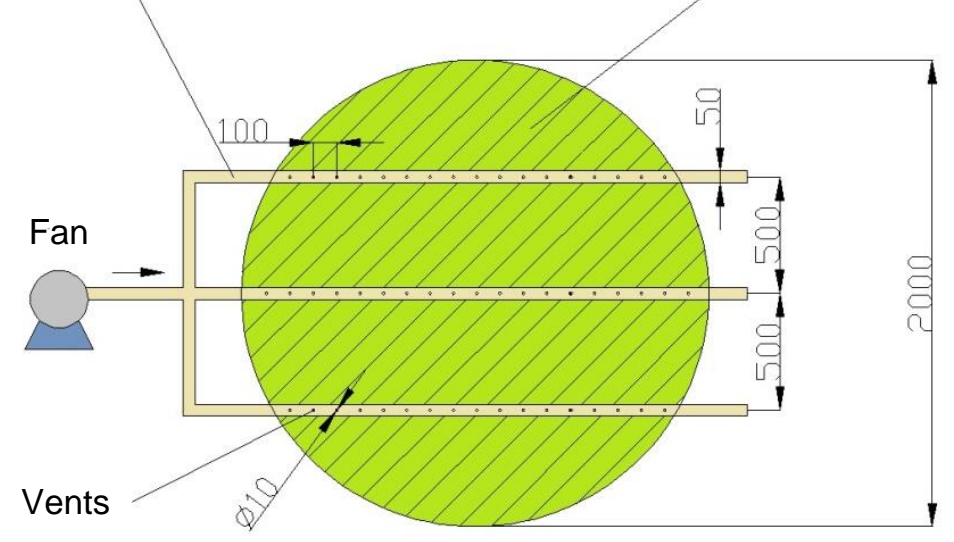

Fig. 1. Structure diagram of composting systems: (a) Structure diagram of four composting systems; (b) Structure diagram of ventilation system

An anti-seepage black membrane was pre-laid on the floor of the fermentation site. Mass transfer systems, which mainly consisted of a ventilation fan, ducts, and vents, were installed above the black membrane (Fig. 1b). The long fork-shaped polypropylene- 
random ventilation ducts with a diameter of $\Phi=50 \mathrm{~mm}$ were adopted (Fig. 1b). There were three vents with a diameter of $5 \mathrm{~mm}$ in a circular section, and the spacing between the two vents was $100 \mathrm{~mm}$. All mass transfer systems used the ventilation system. The intermittent forced ventilation strategy was adopted, and the ventilation rate was $0.5 \mathrm{~L} /(\mathrm{min} \cdot \mathrm{kg}$ of organic matter, $[\mathrm{OM}]$ ). Ventilation lasted for $30 \mathrm{~min}$, and the rest period lasted for $30 \mathrm{~min}$. All treatments used the same ventilation system and strategy.

A semipermeable fermentation membrane was used in the present study. The membrane was composed of the following three layers: inner and outer layers of polyester fibers, and the expanded polytetrafluoroethylene (e-PTFE) was sandwiched between them. The pores of the e-PTFE were $0.2 \mu \mathrm{m}$ in diameter. Owing to its structure and unwanted fouling processes caused by water-logging, the membrane was waterproof and windresistant. The membrane also acted as a barrier against odors and other gaseous substances escaping from the fermentation material.

Solid samples from the aerobic composting pile were collected on the initial day and days 10, 20, 30, 40, and 50. Samples were taken from five different sites on the surface of the composting pile and were mixed for later use. The samples were stored at $-80{ }^{\circ} \mathrm{C}$ for microbial detection and $-20{ }^{\circ} \mathrm{C}$ for the determination of physical and chemical indicators. The greenhouse system adopted the common structural form of the steel frame support and the PVC membrane cover used in rural China.

\section{Chemical Analysis}

The TS and VS were analyzed using the standard methods of the American Public Health Association (2005). The moisture content was measured by placing the sample in an oven at $105^{\circ} \mathrm{C}$ to obtain a dried product with a constant weight (Tian et al. 2012). The mass fractions of total carbon and total nitrogen in the samples were analyzed using an elemental analyzer (Vario EL III, Elementar, Langenselbold, Germany). The pH and electrical conductivity were measured using an S470-K multi-parameter meter (Mettler Toledo, Shanghai, China). The GI was determined by referring to an existing method (Sun et al. 2018). OM was used to burn the sample in a muffle furnace at $600{ }^{\circ} \mathrm{C} \pm 20{ }^{\circ} \mathrm{C}$ for 3 $\mathrm{h}$ to a constant weight. All the resulting values are the means of at least three replicate analyses. The temperature was monitored and recorded using a temperature sensor (JWB/33, ColliHigh, Beijing, China), with an accuracy of $\pm 0.2 \% \mathrm{~F} \cdot \mathrm{S}$, and a data acquisition module (KL-M4542B, ColliHigh, Beijing, China).

\section{RESULTS AND DISCUSSION}

\section{Changes in Temperature of Feedstock during Composting}

The temperature of the four groups quickly reached the peak values on the second day and then gradually decreased (Fig. 2). The temperature of the OV, OMV, GV, and GMV groups reached the highest temperature on the $2^{\text {nd }}$ day, and then they reached the temperatures $56.9,60.8,58.6$, and $63.4{ }^{\circ} \mathrm{C}$, respectively. The composting temperature stabilized and was close to the surrounding temperature after 35 days for the OMV and GMV groups and after 40 days for the OV and GV groups. According to Wang et al. (2021), the period with the optimal temperature range for composting (50 to $60{ }^{\circ} \mathrm{C}$ ), i.e., the thermophilic period, should be maintained for at least 10 days to ensure that the compost product is sanitized. The thermophilic period for the OV, OMV, GV, and GMV groups lasted for $6,13,11$, and 20 days, respectively. The thermophilic period was more 
than 10 days for all the treatments except for the OV groups. The GMV and OMV groups covered with the semipermeable membrane had higher composting temperature peaks and longer high-temperature durations. The greenhouse insulation measures increased the average temperature of the semipermeable membrane composting by $4.89{ }^{\circ} \mathrm{C}$, and the hightemperature duration was delayed by 7 days. These two groups required a shorter time to complete composting than the GV and OV groups. The GMV group had the highest temperature peak and the longest duration of high-temperature period.

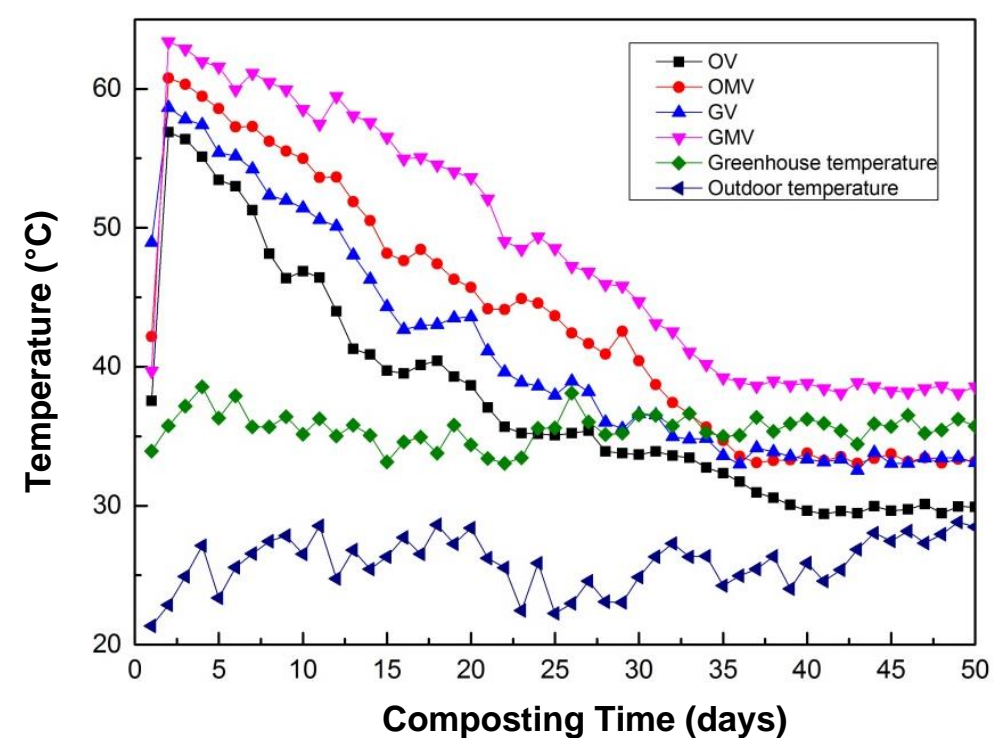

Fig. 2. Composting temperature changes of feedstock

The composting temperature is commonly used to assess the composting efficiency and compost product stability (Rich et al. 2018). The change in temperature during composting depends on the microbial decomposition of readily biodegradable organic substances, material shape, and insulation form (Zhou et al. 2018). The membrane addition causes a rapid rise in the temperature and a long thermophilic phase, consequently accelerating the composting process and increasing the composting efficiency. In this study, the temperature in the greenhouse was higher and more stable than the atmospheric temperature, forming an insulation layer to prevent temperature loss. Especially in winter, when the outside temperature was low, the greenhouse environment had great advantages. With no covering of the semipermeable membrane or greenhouse facilities, the OV group was directly affected by the changes in atmospheric temperature and rainfall, leading to accelerated heat loss and failure to meet the temperature requirements for fermentation. Therefore, it is best to cover the system with a membrane for ventilation. Otherwise, the temperature of the pile in the middle and late stages would be low, and the decomposition would be poor.

\section{Changes in the OM of Feedstock during Composting}

Changes in the OM content can indirectly characterize the composting process and maturity (Benito and Greger 2017). The OM content decreased gradually as composting progressed and then stabilized (Fig. 3). The OM decomposition rates of the OV, OMV, $\mathrm{GV}$, and GMV groups were $14.2 \%, 20.9 \%, 19.8 \%$, and $26.0 \%$, respectively. 


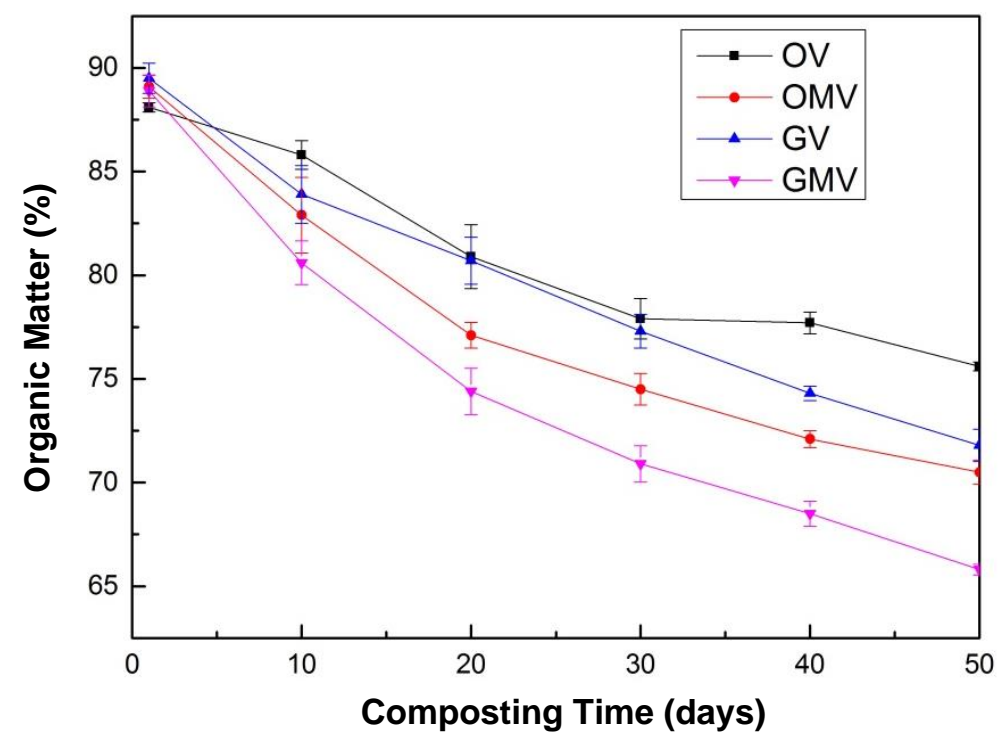

Fig. 3. Organic Matter changes of feedstock during composting

In the first 30 days of composting, the content of easily decomposable OM in each treatment group was high, and the growth of microorganisms and the strong metabolism promoted a rapid decline in the decomposition rate of OM. Owing to the effect of the semipermeable membrane, the decomposition rate of OM in the membrane-covered groups (OMV and GMV) was higher than that of the uncovered groups (OV and GV). The GMV group exhibited the highest OM decomposition rate because of the dual effect of the membrane insulation and solar heating, which increased the decomposition rate of OM by $11.8 \%$ compared with that in the OV group. After day 30, the degradation rate in each treatment group was slow. The OV group did not degrade OM during this interval because of the absence of any insulation measures in the open air, and the rainwater brought pollution and cooling of the fermentation environment. As a result, the activity of microorganisms was inhibited, resulting in the lowest degradation rate. The fermentation temperature was higher, the duration was longer, the OM degradation rate was higher, and the stability was reached faster. The faster degradation of total OM was more conducive to the stability of the compost quality.

\section{Changes in pH and Electrical Conductivity of Feedstock during Composting}

The $\mathrm{pH}$ is an important indicator of the growth and reproduction of microorganisms. The effects of different treatment methods on $\mathrm{pH}$ during composting are shown in Fig. 4. The $\mathrm{pH}$ value of each treatment dropped first and then increased rapidly and slowly decreased to reach a steady trend. At the initial stage of fermentation, the $\mathrm{pH}$ of each treatment was neutral. With the progress of composting, the $\mathrm{pH}$ of each treatment reached a maximum value of approximately 9 on day 30. Then, the $\mathrm{pH}$ showed a slow downward trend with an increase in composting time and stabilized at approximately 8 at the end of composting. The final $\mathrm{pH}$ values of the $\mathrm{OV}, \mathrm{OMV}, \mathrm{GV}$, and GMV groups were $7.89,8.24,8.26$, and 8.18 , respectively.

In the first 10 days of composting, there was more easily degradable OM in the material, and insufficient oxygen supply led to incomplete degradation. A large amount of metabolite organic acid was stored in the feedstock pile, which caused the $\mathrm{pH}$ value to decrease. The membrane-covered treatment groups (OMV and GMV) allowed higher 
temperature and higher microbial activity, bringing the incomplete degradation of OM and the accumulation of organic acid. These led the $\mathrm{pH}$ of the OMV and GMV groups to decrease to the lowest level around 5. As the composting microorganisms continued to degrade OM, some organic acids were volatilized, and some were gradually decomposed. At the same time, ammoniation of nitrogen-containing OM caused the $\mathrm{pH}$ of each group to rise to the highest value. In the later stage of composting, owing to the continuous volatilization of ammonia, the nitrification of microorganisms consumed ammonia and released $\mathrm{H}^{+}$, which slightly decreased and stabilized the $\mathrm{pH}$ of the composting feedstock (Awasthi et al. 2018). Except for the OV group, the $\mathrm{pH}$ values of the other three groups stabilized quickly.

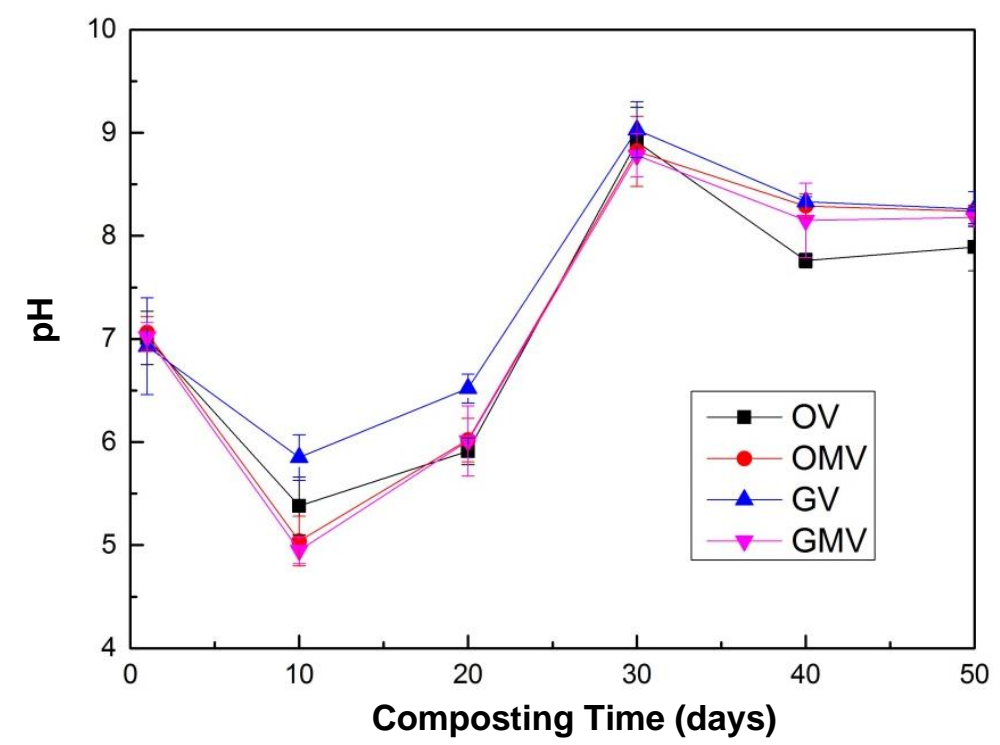

Fig. 4. pH Value changes of feedstock during composting

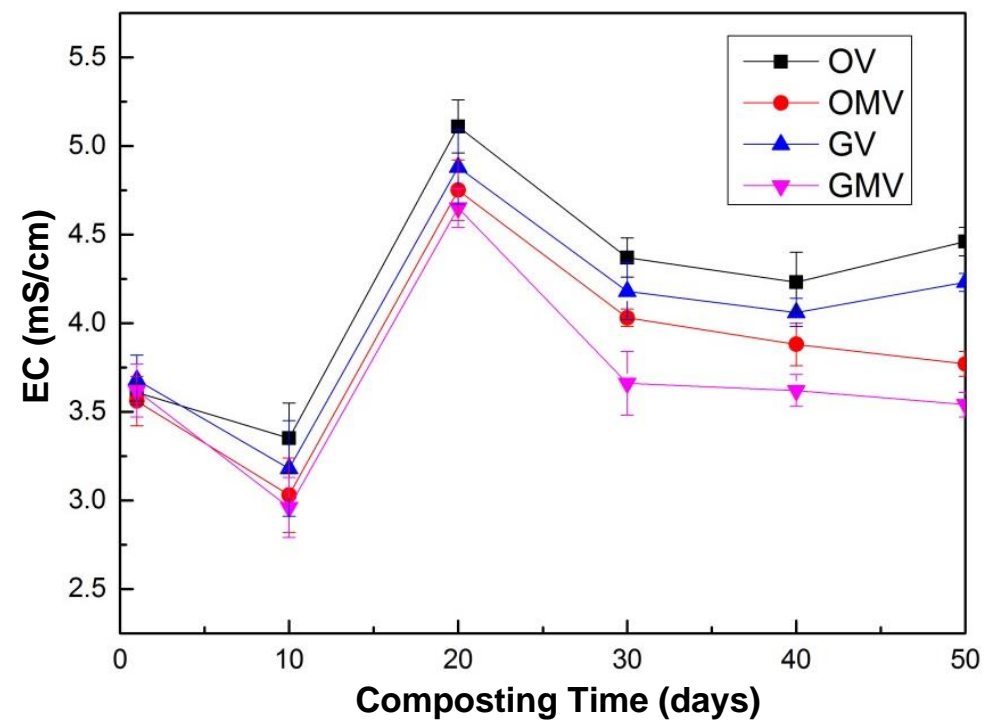

Fig. 5. Electrical conductivity changes of feedstock during composting 
The electrical conductivity (EC) of the composting extract reflects the salt content of the composting feedstock. As shown in Fig. 5, the change in EC was similar to the change in $\mathrm{pH}$; the EC first decreased, then increased, and then decreased as composting progressed. The initial EC value of each treatment was approximately $3.5 \mathrm{mS} / \mathrm{cm}$. In the early stage of composting, as the temperature increased. A large number of organic nutrients were consumed by microorganisms, resulting in a slight decrease in EC. Subsequently, the EC was increased by the release of mineral salts, such as phosphate and ammonium ions, caused by the mineralization of organic substances. At the end of the composting, due to the volatilization of ammonia and the precipitation of mineral salts, the EC continued to decrease during composting (Fang et al. 1999). Except for the OV and GV groups, the final EC value of each test group was less than $4 \mathrm{mS} / \mathrm{cm}$ (Li et al. 2020). The EC value of the OV group increased during the late fermentation period, owing to the rainy season in that period. This caused the raw materials to be contaminated by rainwater, and part of the soluble salt seeped into the interior of the stack. The OMV and GMV groups could control the EC value of the compost product within a reasonable range, which met the standards of compost maturity. The EC value of the GMV group was the lowest, which was more conducive to plant growth.

\section{Changes in the $\mathrm{C} / \mathrm{N}$ Ratio of Feedstock during Composting}

The changes in the $\mathrm{C} / \mathrm{N}$ of the four treatment groups are shown in Fig. 6. Overall $\mathrm{C} / \mathrm{N}$ first decreased and then stabilized. During composting, $\mathrm{C} / \mathrm{N}$ of the $\mathrm{OV}, \mathrm{OMV}, \mathrm{GV}$, and GMV groups decreased from 29.2 to 23.07, 19.56, 20.73, and 17.81, respectively. Under the action of microorganisms, nitrogen was continuously mineralized and transformed into ammonium nitrogen.

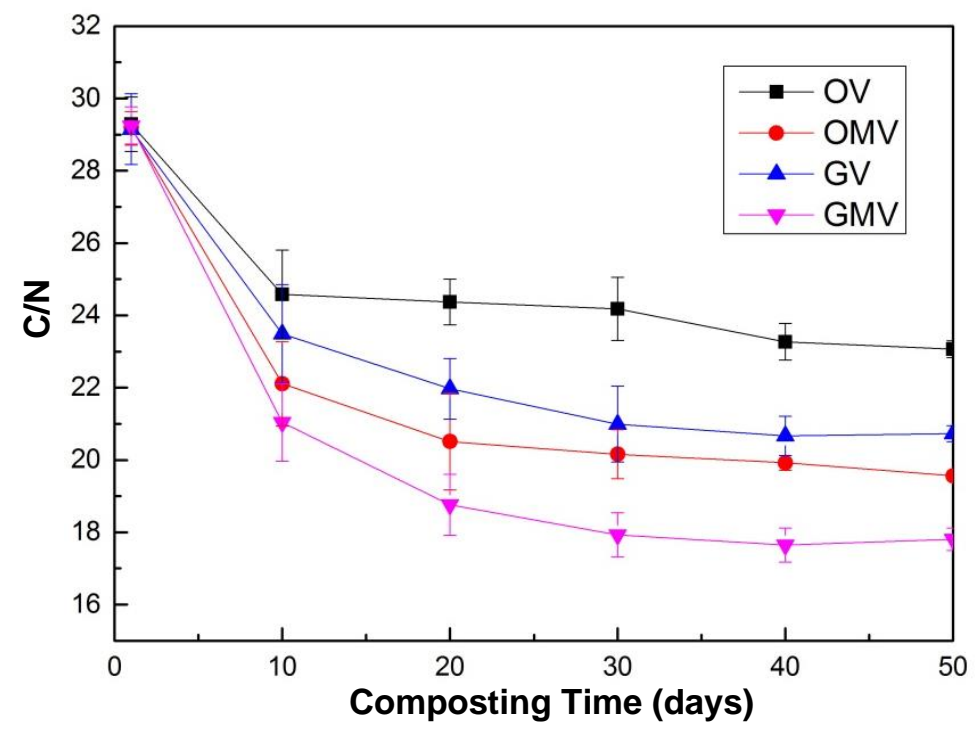

Fig. 6. Carbon-nitrogen ratio changes of feedstock during composting

At high temperatures and $\mathrm{pH}$, ammonium nitrogen was volatilized in the form of ammonia, causing the nitrogen content of each group to decrease. This also led to a decrease in $\mathrm{C} / \mathrm{N}$ during composting. In the early stage of fermentation, carbon-containing OM decomposed quickly, resulting in a rapid decrease in $\mathrm{C} / \mathrm{N}$. The temperature peak in the GMV group was higher, and the duration was longer than in the other groups. This led to 
the rapid decomposition of OM in the GMV group, the fastest and largest decline in $\mathrm{C} / \mathrm{N}$, and the fastest entry into the stable stage. The decomposition rates of OM in the OMV and GV groups were equivalent. The OMV group entered the stable stage faster than the GV group. Due to the short high-temperature stage, the OV group had the slowest rate of decrease in $\mathrm{C} / \mathrm{N}$.

The $\mathrm{C} / \mathrm{N}$ ratio is one of the most commonly used parameters for evaluating composting maturity. $\mathrm{C} / \mathrm{N}$ of less than 20 at the end of composting indicates maturity. However, when composting is completed, the solid-phase $\mathrm{C} / \mathrm{N}$ ratio is affected by the characteristics of the raw composting materials and the operating parameters of the composting process (Guo et al. 2012). The $T$ value is an index for evaluating composting ( $T$ is the ratio of $\mathrm{C} / \mathrm{N}$ at the end of composting to $\mathrm{C} / \mathrm{N}$ at the beginning of composting). Itavaara et al. (1997) suggested that a $T$ value between 0.53 and 0.72 during composting indicates compost maturity. The $T$ values of the $\mathrm{OV}, \mathrm{OMV}, \mathrm{GV}$, and GMV groups were $0.79,0.67,0.71$, and 0.61 , respectively. The $T$ values of the OMV, GV and GMV groups met the requirements of compost maturity. The decomposition of $\mathrm{OM}$ in these groups promoted by microorganisms activity because of the higher temperature and thermophilic period. In the OV group, the low peak temperature and short high-temperature period in the early stage affected the decomposition rate of OM and resulted in a $T$ value that did not attain a designated standard.

\section{Changes in Germination Index of Feedstock during Composting}

As shown in Fig. 7, the GI of the OV, OMV, GV, and GMV groups at the end of composting was $75.9 \%, 87.7 \%, 85.1 \%$, and $92.5 \%$, respectively. With the progress of composting, the GI value of each group started to increase from the initial $40 \%$ due to the decomposition of short-chain volatile organic acids and the volatilization of ammonia. Because of the different membrane-covered facilities of each group, the temperature and microbial activity in each pile were different, which in turn affected the decomposition of low-molecular-weight substances such as $\mathrm{NH}_{3}$ and organic acids by microorganisms, and thus the GI value of the compost product.

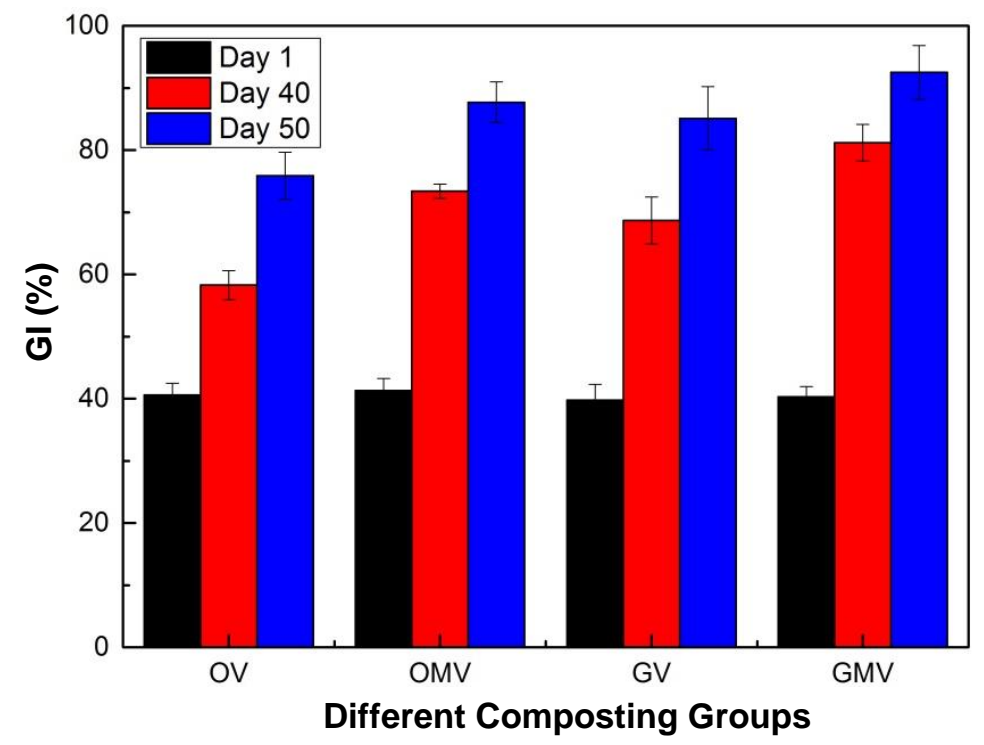

Fig. 7. Germination index changes of feedstock during composting 
The GI value of the GMV group was higher than $80 \%$ on the $40^{\text {th }}$ day, indicating that the composts were not toxic to plants (Riffaldi et al. 1988). Except for the OV group, the final GI values of the remaining three groups were higher than $80 \%$ on the $50^{\text {th }}$ day. The $\mathrm{OM}$ and secondary metabolites in the materials were further decomposed by microorganisms, and the content of the biologically toxic substances gradually decreased, indicating the gradual weakening of the inhibitory effect on seed germination. The GMV group had the highest GI value and was $4.8 \%$ higher than the GI of the OMV group, which indicated that the semipermeable membrane-covered systems with the greenhouse can kill more pathogens at higher temperatures. Therefore, it was a suitable aerobic fermentation environment for the feedstock under the dual effects of semipermeable membrane-covered systems and greenhouses, which can promote composting maturity and shorten the compost maturity cycle.

\section{Changes in Microbiological Indicators of Feedstock during Composting}

The changes of microbiological indicators during composting are shown in Table 3. On the $40^{\text {th }}$ day of the composting, the two microbiological indicators of GMV group met the requirements of organic fertilizer (NY525, 2021). The standard required that fecal coliforms were less than or equal to $100 \mathrm{MPN} / \mathrm{g}$, and the mortality of roundworm eggs were more than or equal to $95 \%$. The other three groups were all substandard. At the end of the composting test, the mortality of roundworm eggs in the four groups reached $100 \%$. The number of fecal coliforms in the OV group and GV group were $260 \mathrm{MPN} / \mathrm{g}$ and 130 $\mathrm{MPN} / \mathrm{g}$ (most probable number per gram), respectively. The number of fecal coliforms in the OMV group was not detected, which met the requirements of organic fertilizers.

Table 3. Microbiological Indicators of Feedstock during Composting

\begin{tabular}{|c|c|c|c|c|}
\hline Treatments & $\begin{array}{c}\text { Mortality of } \\
\text { roundworm eggs } \\
\text { on day } 40(\%)\end{array}$ & $\begin{array}{c}\text { Mortality of } \\
\text { roundworm eggs } \\
\text { on day } 50(\%)\end{array}$ & $\begin{array}{c}\text { Number of fecal } \\
\text { coliforms on } \\
\text { day } 40(\mathrm{MPN} / \mathrm{g})\end{array}$ & $\begin{array}{c}\text { Number of fecal } \\
\text { coliforms on day } \\
50(\mathrm{MPN} / \mathrm{g})\end{array}$ \\
\hline OV & 88 & 100 & 1600 & 260 \\
\hline OMV & 100 & 100 & 90 & $/$ \\
\hline GV & 95 & 100 & 800 & 130 \\
\hline GMV & 100 & 100 & $/$ & $/$ \\
\hline
\end{tabular}

\section{CONCLUSIONS}

1. The double insulating measures of the membrane-covered and greenhouse systems were able to extend the effective high-temperature period of fermentation (temperature $\geq 50{ }^{\circ} \mathrm{C}$ ) by 14 days, increase the peak temperature by $6.53{ }^{\circ} \mathrm{C}$, and shorten the fermentation cycle by 5 days.

2. The double insulating measure could increase the decomposition rate of organic matter $(\mathrm{OM})$ in raw materials by $11.8 \%$, accelerate the degradation efficiency of $\mathrm{OM}$, and help stabilize the quality of composting.

3. The combination of permeable membrane cover within a greenhouse was more conducive to the harmless treatment of feedstocks than the traditional aerobic composting, reducing the content of biologically toxic substances, remarkably promoting compost maturity, and shortening the compost fermentation cycle. The low 
temperature in the early stage of open composting may affect the decomposition of OM and resulted in a $T$ value that cannot attain the maturity standard. Future studies are proposed to elucidate the mechanism underlying the reduction in gas emission based on the dual strengthening measures of semipermeable membrane and greenhouse.

\section{ACKNOWLEDGMENTS}

This work was supported by the Fundamental Research Funds for the Central Public-interest Scientific Institution Basal Research Fund (No. S202004-01), Central Public-interest Scientific Institution Basal Research Fund (No. Y2021XC04-03), the Key Research and Development Program of Hebei Province (No. 20327313D), and the Modern Agricultural Machinery Equipment and Technology Demonstration and Promotion Program of Jiangsu Province (No. NJ2021-57).

\section{REFERENCES CITED}

Ajmal, M., Aiping, S., Awais, M., Ullah, M., S., Saeed, R., Uddin, S., Ahmad, I., Zhou, B., and Xu, Z.-H. (2020). "Optimization of pilot-scale in-vessel composting process for various agricultural wastes on elevated temperature by using Taguchi technique and compost quality assessment," Process Saf. Environ. 140, 34-45. DOI: 10.1016/j.psep.2020.05.001

Awasthi, M., Awasthi, S., Wang, Q., Wang, Z., Lahori, A., Ren, X., Chen, H., Wang, M., Zhao, J., and Zhang, Z. (2018). "Influence of biochar on volatile fatty acids accumulation and microbial community succession during biosolids composting," Bioresource Technol. 251, 158-164. DOI: 10.1016/j.biortech.2017.12.037

Benito, P., and Greger, M. (2017). "Influence of the substrate/inoculum ratio on process stability and performance during batch digestion of grass silage," Chem. Ing. Technol. 89, 724-732. DOI: 10.1002/cite.201600008

Chen, H., Awasthi, M. K., Liu, T., Zhao, J., Ren, X., Wang, M., Duan, Y., Awasthi, S., and Zhang, Z. (2018). "Influence of clay as additive on greenhouse gases emission and maturity evaluation during chicken manure composting," Bioresource Technol. 266, 82-88. DOI: 10.1016/j.biortech.2018.06.073

Chen, W., Luo, S., Du, S., Zhang, M., Cheng, R., and Wu, D. (2020). "Strategy to strengthen rural domestic waste composting at low temperature: Choice of ventilation condition," Waste Biomass Valori. 11, 1-17. DOI: 10.1007/s12649-020-00943-4

Chen, Y., Yu, F., Liang, S., Wang, Z., Liu, Z., and Xiong, Y. (2014). "Utilization of solar energy in sewage sludge composting: fertilizer effect and application," Waste Manage. 34, 2014-2021. DOI: 10.1016/j.wasman.2014.06.029

Dhamodharan, K., Varma, V., Veluchamy, C., Pugazhendhi, A., and Rajendran, K. (2019). "Emission of volatile organic compounds from composting: A review on assessment, treatment and perspectives," Science of the Total Environment 695, article no. 133725. DOI: 10.1016/j.scitotenv.2019.133725

Fang, M., Wong, J. C., Ma, K. K., and Wong, M. H. (1999). "Co-composting of sewage sludge and coal fly ash: nutrient transformations," Bioresource Technol. 67, 19-24.

DOI: 10.1016/S0960-8524(99)00095-4

Garcia-González, M. C., and Vanotti, M. B. (2015). "Recovery of ammonia from swine 
manure using gas-permeable membranes: Effect of waste strength and $\mathrm{pH}$," Waste Manag. 38, 455-461. DOI: 10.1016/j.wasman.2015.01.021

Gonzalez, I., Robledo-Mahon, T., Silva-Castro, G.A., Rodríguez-Calvo, A., Gutierrez, M., Martín, M., Chica, A., and Calvo, C. (2016). "Evolution of the composting process with semi-permeable film technology at industrial scale," J. Clean. Prod. 115, 245-254. DOI: 10.1016/j.jclepro.2015.12.033

Guo, R., Li, G., Jiang, T, Schuchardt, F., Chen, T., Zhao, Y., and Shen, Y. (2012). "Effect of aeration rate, $\mathrm{C} / \mathrm{N}$ ratio and moisture content on the stability and maturity of compost," Bioresource Technol. 112, 171-178. DOI: 10.1016/j.biortech.2012.02.099

Huang, G., Fang, C., Ma, S., and Han, L. (2018). "Storage stability of micro-aerobic coupling functional membrane and gas emission reduction of dairy manure," Transactions of the Chinese Society for Agricultural Machinery. 49, 335-341. DOI: 10.6041/j.issn.1000-1298.2018.07.040

Itavaara, M., Vikman, M., and Venelampi, O. (1997). "Windrow composting of biodegradable packaging materials," Compost Science Utilization 5, 84-92.

Komilis, D. P., Ham, R. K., and Park, J. K. (2004). "Emission of volatile organic compounds during composting of municipal solid wastes," Water Res. 38, 1707-1714. DOI: 10.1016/j.watres.2003.12.039

Li, Y., Liu, Y., Yong, X., Wu, X., and Zhou, J. (2020a). “Odor emission and microbial community succession during biogas residue composting covered with a molecular membrane," Bioresource Technol. 297, article no. 122518. DOI: 10.1016/j.biortech.2019.122518

Li, X., Shi, X., Lu, M., Zhao, Y., Guo, R., and Peng, H. (2020b). "Improved nitrogen conservation capacity during composting of dairy manure amended with oil shale semi-coke as the porous bulking agent," J. Hazard. Mater. 388, 121742. DOI: 10.1016/j.jhazmat.2019.121742

Lin, H., Ye, J., Sun, W., Yu, Q., Wang, Q., Zou, P., Chen, Z., Ma, J., Wang, F., and Ma, J. (2020). "Solar composting greenhouse for organic waste treatment in fed-batch mode: Physicochemical and microbiological dynamics," Waste Manage. 113, 1-11. DOI: 10.1016/j.wasman.2020.05.025

Ma, S., Sun, X., Fang, C., He, X., Han, L., and Huang, G. (2018). "Exploring the mechanisms of decreased methane during pig manure and wheat straw aerobic composting covered with a semi-permeable membrane," Waste Manag. 78, 393-400. DOI: 10.1016/j.wasman.2018.06.005

Ma, S., Xiong, J., Cui, R., Sun, X., and Huang, G. (2020). "Effects of intermittent aeration on greenhouse gas emissions and bacterial community succession during large-scale membrane-covered aerobic composting," J. Clean. Prod. 266, 121551. DOI: $10.1016 /$ j.jclepro.2020.121551

Ma, S., Xiong, J., Wu, X., Liu, H., Han, L., and Huang, G. (2021). "Effects of the functional membrane covering on the gas emissions and bacterial community during aerobic composting," Bioresource Technol. 340, article no. 125660. DOI: 10.1016/j.biortech.2021.125660

NY 525 (2021). "Organic fertilizer," Ministry of Agriculture and Rural Affairs of the People's Republic of China, Beijing, China.

Poblete, R., Salihoglu, G., and Salihoglu, N. K. (2021). "Incorporation of solar-heated aeration and greenhouse in grass composting," Environ. Sci. Pollut. R. 28, 1-12. DOI: 10.1007/S11356-021-12577-7

Rich, N., Bharti, A., and Kumar, S. (2018). "Effect of bulking agents and cow dung as 
inoculant on vegetable waste compost quality," Bioresource Technol. 252, 83-90.

DOI: $10.1016 /$ j.biortech.2017.12.080

Riffaldi, R., Saviozzi, A., and Levi-Minzi, R. (1988). "Water extracts of fresh and mature farmyard manure,” Biol. Wastes. 23, 65-72. DOI: 10.1016/0269-7483(88)90045-6

Robledo-Mahón, T., Aranda, E., Pesciaroli C., Rodríguez-Calvo, A., Gloria Andrea Silva-Castro, González-López, J., and Calvo, C. (2018). "Effect of semipermeable cover system on the bacterial diversity during sewage sludge composting," $J$. Environ. Manage. 215, 57-67. DOI: 10.1016/j.jenvman.2018.03.041

Robledo-Mahón, Gómez-Silván, C., Andersen, G. L., Calvo, C., and Aranda, E. (2020). "Assessment of bacterial and fungal communities in a full-scale thermophilic sewage sludge composting pile under a semipermeable cover," Bioresource Technol. 298, 122550. DOI: 10.1016/j.biortech.2019.122550

Schlegelmilch, M., Streese, J., Biedermann, W., Herold, T., and Stegmann, R. (2005). "Odour control at biowaste composting facilities," Waste Manag. 25, 917-927. DOI: 10.1016/j.wasman.2005.07.011

Sun, X., Ma, S., Han, L., Li, R., Schlick, U., Chen, P., and Huang, G. (2018). "The effect of a semi-permeable membrane-covered composting system on greenhouse gas and ammonia emissions in the Tibetan Plateau," J. Clean. Prod. 204, 778-787. DOI: 10.1016/j.jclepro.2018.09.061

Tian, W., Li, L., Liu, F., Zhang, Z., Yu, G., Shen, Q., and Shen, B. (2012). “Assessment of the maturity and biological parameters of compost produced from dairy manure and rice chaff by excitation-emission matrix fluorescence spectroscopy," Bioresource Technol. 110, 330-337. DOI: 10.1016/j.biortech.2012.01.067

Turan, N. G., Akdemir, A., and Ergun, O. N. (2009). "Removal of volatile organic compounds by natural materials during composting of poultry litter," Bioresource Technol. 100, 798-803. DOI: 10.1016/j.biortech.2008.07.010

Wang, W., Zhang, L., and Sun, X. (2021). "Improvement of two-stage composting of green waste by addition of eggshell waste and rice husks," Bioresource Technol. 320, article no. 124388. DOI: 10.1016/j.biortech.2020.124388

Yang, L., Li, A., Yuan, C., Yang, C., Feng, L., and Pang, C. (2020). "Review on the application of semi-permeable membrane-covered composting system," Acta Scientiae Circumstantia. 40, 3559-3564. DOI: 10.13671 /j.hjkxxb.2020.0415

Zhou, H., Zhao, Y., Yang, H., Zhu, L., Cai, B., Luo, S., Cao, J., and Wei, Z. (2018). "Transformation of organic nitrogen fractions with different molecular weights during different organic wastes composting," Bioresource Technol. 262, 221-228. DOI: $10.1016 /$ j.biortech.2018.04.088

Article submitted: September 30, 2021; Peer review completed: November 30, 2021; Revised version received and accepted: December 22, 2021; Published: January 5, 2022. DOI: 10.15376/biores.17.1.1173-1186 